Marquette University

e-Publications@Marquette

College of Nursing Faculty Research and

Publications

Nursing, College of

2011

\title{
The Effects of Positive Cognitions on the Relationship between Alienation and Resourcefulness in Nursing Students in Egypt
}

\author{
Abir K. Bekhet \\ Marquette University, abir.bekhet@marquette.edu \\ Mervat ElGuenidi \\ Alexandria University \\ Jaclene A. Zauszniewski \\ Case Western Reserve University
}

Follow this and additional works at: https://epublications.marquette.edu/nursing_fac

Part of the Nursing Commons

\section{Recommended Citation}

Bekhet, Abir K.; ElGuenidi, Mervat; and Zauszniewski, Jaclene A., "The Effects of Positive Cognitions on the Relationship between Alienation and Resourcefulness in Nursing Students in Egypt" (2011). College of Nursing Faculty Research and Publications. 322.

https://epublications.marquette.edu/nursing_fac/322 
Marquette University

e-Publications@Marquette

\title{
Nursing Faculty Research and Publications/College of Nursing
}

This paper is NOT THE PUBLISHED VERSION; but the author's final, peer-reviewed manuscript. The published version may be accessed by following the link in the citation below.

Issues in Mental Health Nursing, Vol. 32, No. 1 (2011): 35-41. DOI. This article is (C Taylor \& Francis and permission has been granted for this version to appear in e-Publications@Marquette. Taylor \& Francis does not grant permission for this article to be further copied/distributed or hosted elsewhere without the express permission from Taylor \& Francis.

\section{The Effects of Positive Cognitions on the Relationship between Alienation and Resourcefulness in Nursing Students in Egypt}

\author{
Abir K. Bekhet \\ College of Nursing, Marquette University, Milwaukee, WI \\ Mervat ElGuenidi \\ Alexandria University, School of Nursing, Alexandria, Egypt \\ Jaclene A. Zauszniewski \\ Bolton School of Nursing, Case Western Reserve University, Cleveland, $\mathrm{OH}$
}

\begin{abstract}
Alienation is a subjective state, a feeling of being a stranger, as if one were not one's normal self. It is also a sense of homelessness; a feeling of uneasiness or discomfort, which signifies the person's exclusion from social or cultural participation. Alienation can adversely affect healthy functioning of nursing students. Nursing students are the adolescents of today and the nurses of tomorrow who will
\end{abstract}


deal with human behavior, and their psychological well-being will be important in managing their clients' conditions. Healthy nursing students are likely to become healthy nurses who can then model and promote healthy lifestyles for their patients. This study looked at whether the effects of alienation on adolescents' resourcefulness are influenced by positive cognitions. Zauszniewski's theory of resourcefulness, which is based on the conceptualization of two forms of resourcefulness: personal (self-help) and social (help-seeking) resourcefulness, served as the theoretical framework for the study. A descriptive, correlational, cross-sectional design was used to examine hypothesized relationships among the study variables in a convenience sample of 170 first-year nursing students aged 17 to 20 years. Results showed that positive cognitions had a moderating and a partial mediating effect on the relationship between alienation and resourcefulness. It is imperative for nurse educators to generate interventions to enhance positive cognitions among nursing students.

Adolescents represent a large sector of the Egyptian population; their number is projected to increase from 13.8 million in 2000 to 16.5 million by the year 2020 (POLICY Project, 2003). Adolescence is a stormy period of human development, a time of transition from the immaturity of childhood to the maturity of adulthood, between ages 12 and 20 (Lefton \& Brannon, 2003; Steinberg, 2010). Many interrelated physical, psychological, social, and emotional changes occur in adolescents during this period (Lefton \& Brannon, 2003; Steinberg, 2010).

Mental health in adolescence is marked by achievement of expected developmental milestones in the areas of cognition, emotional stability, socially acceptable coping, and appropriate socialization within and outside the family (Fortinash \& Worret, 2007). In contrast, emotionally disturbed adolescents feel alienated from friends, family, and school. They do not function in the mainstream of adolescent and adult society; their actions are an expression of their feelings of alienation, which they find difficult to deal with in socially approved ways (Rice \& Dolgin, 2008).

Alienation is a subjective state, a feeling of being a stranger, as if one were not one's normal self (Schabracq \& Cooper, 2003); it is also a sense of homelessness (Younger, 1995), a feeling of uneasiness or discomfort, which signifies the person's exclusion from social or cultural participation (Levett-Jones, Lathlean, McMillan, \& Higgins, 2007). Alienation is related to the extent to which one's values, beliefs, and norms articulate with those of the particular group of which one is associated (Levett-Jones, Lathlean, McMillan and Higgins, 2007, p. 163). The phenomenon of alienation is not determined by one symptom but by a set of associated symptoms; as Dean (1961) stated, "It may very well be that alienation is not a unitary phenomenon but a syndrome" (p. 754). Alienation has been associated with risky driving behavior among adolescents (Gulliver \& Begg, 2007), and in a recent study of 5205 adolescents, Rayce and colleagues (2009) found a significant correlation between aspects of alienation and high symptom load (having at least one psychological and/or physical symptom daily). Thus, it is recommended that alienation should be taken into account in developing health-promoting interventions for adolescents (Rayce, Holstein, \& Kreiner, 2009). The purpose of this study is to determine whether the effects of alienation (intrinsic factor) on adolescents' personal and social resourcefulness was influenced (i.e., mediated or moderated) by positive cognitions (process regulator). The study is a first step toward developing interventions to strengthen positive cognitions and teach alienated adolescents how to become resourceful. 
Nursing students are the adolescents of today and the nurses of tomorrow who will deal with human behavior, and their psychological well-being will be important in managing their clients' conditions. Healthy nursing students are likely to become healthy nurses who can then model and promote healthy lifestyles for their patients (Ahmadi, Toobaee, \& Alishahi, 2004). A study by Bekhet et al. (2005) examined alienation related factors in a sample of 600 diploma nursing students in 14 different schools of nursing in Alexandria, Egypt. The study found that more than half of the nursing students were alienated, and levels of alienation were higher in female students and those with social and physical problems. Similarly, a study by Ahmadi and colleagues (2004) found that a significant number of Middle Eastern nursing students were mildly to moderately depressed and felt hopeless (44\%) some of them had suicidal thoughts. In Australia and the United Kingdom, 18 nursing students' experiences of belonging while in their clinical placement was explored, and the results indicated that they strongly believed belonging was a prerequisite for clinical learning (Levett-Jones \& Lathlean, 2008).

Resourcefulness, which involves the ability to maintain independence in daily tasks even in potentially adverse situations (Rosenbaum, 1990) and to seek help from others when unable to function independently (Zauszniewski, 2006), may be important in helping nursing students avoid or overcome alienation. Highly resourceful persons report more adaptive and better social role functioning, deal with life events more effectively, and have better daily task performance. Furthermore, they reported better self-help, life satisfaction, and quality of life (Bekhet, Zauszniewski, \& Wykle, 2008; Zauszniewski, 1994, 1999, 2006). Thus, our goal should be to promote resourcefulness among nursing students to help them overcome alienation.

Positive cognitions are positive thinking patterns that are thought to enhance mental health. Studies have shown that positive cognitions decrease the effects of some adverse factors (Bekhet et al., 2008; Zauszniewski, McDonald, Krafcik, \& Chung, 2002) and may provide a sense of control in uncertain situations and reduce depression (Link, Robbins, Mancuso, \& Charlson, 2004; McGrath, Jordens, Montgomery, \& Kerridge, 2006). Thus, nursing students who view new and challenging situations to be opportunities for personal growth (i.e., have positive cognitions) might be expected to be more resourceful and deal with the emotional disturbances of adolescence more positively. However, previous studies have not examined whether the relationship between alienation and resourcefulness is affected by positive cognition.

Zauszniewski's (2006) theory of resourcefulness served as the theoretical framework for this study. Zauszniewski's theory is based on the conceptualization of two forms of resourcefulness: personal (self-help) and social (help-seeking) resourcefulness. Resourcefulness is defined as a collection of cognitive and behavioral skills that are used to attain, maintain, or regain health. Major constructs in the theory of resourcefulness include antecedents or contextual factors (intrinsic and extrinsic), intervening variables or process regulators (cognitions, affect, motivation, and energy), and quality of life outcomes (physical, psychological, and social functioning) (Zauszniewski, 2006).

Intrinsic factors affecting personal and social resourcefulness are intrapersonal and emerge from the internal environment (Zauszniewski, 2006). The intrinsic factor examined in this study was alienation. Process regulators are intervening variables that may mediate or moderate the effects of the intrinsic or extrinsic factors on personal and social resourcefulness. The process regulators examined in this study are positive cognitions. 


\section{METHOD}

\section{Sample}

The convenience sample included 170 adolescent first-year nursing students aged 17 to 20 years old (representing late adolescence), who were admitted to the Faculty of Nursing, Alexandria University, Alexandria, Egypt. The sample size was adequate to test the mediating and moderating effects of positive cognitions with a power of .80 and significance of .05 .

Approval for this study was obtained from the University Institutional Review Board and from the faculty of nursing. Before the lecture, the researcher met the students in the class and explained the purpose of the study and assured them that their responses would be confidential and that refusal to participate would not affect their grades. A total of 205 questionnaires were distributed to the class and the students were asked to return them at their convenience in a designated place rather than to a specific person so that the identity of the student would not be revealed. A total of 180 questionnaires were returned; 10 were excluded because students did not respond to two or three whole scales. The final sample was, thus, 170 students.

\section{Instruments}

Alienation was measured by the Afaf Mohamed Abd El Monem Scale (AMAS; Abd El Monem, 1988), which is reliable, valid, and has been tested with an Egyptian population (Bekhet, Abd El-Dayem, Naguib, \& ElGuinidy, 2005). The AMAS has been tested in male and female Egyptian College students (faculty of arts) aged 17-23 years old and the reliability of the AMAS was found to be alpha = .76 (Abd El Monem, 1988). Construct validity was demonstrated by significant correlations in the expected directions $(p<.001)$ with measures of adaptive functioning, social withdrawal, creative thinking, and depression among males and females Egyptian college students aged $17-23$ years $(r s=-.54, .57,-.60$, .57 , respectively) (Abd El Monem, 1988). The AMAS also has been tested among male and female diploma nursing students (three years of high school nursing after middle school) aged 17-21 in Alexandria, Egypt and the reliability of the study was alpha $=.87$ (Bekhet et al., 2005).

The scale consists of 41 items scored on a 5-point Likert Scale from strongly agree (0) to strongly disagree (4). Scores may range from 0 to 164 after reverse coding four items. Higher scores indicate greater alienation. The Alienation Scale assesses six alienation symptoms: psychological loneliness, social isolation, powerlessness, normlessness, purposelessness, and meaninglessness. Examples of items are: "I feel lonely even when people are around" and "My life has no meaning at all." Cronbach's alpha for The Alienation Scale was .89 in this study.

Positive cognitions were measured by the Depressive Cognition Scale (DCS) developed by Zauszniewski (1995). Example of the scale items are, "I'm hopeful about my future," "I think my life is pretty full," "I feel useful and needed," and "I believe that life is worth living." The scale has been used this way in previous research (Zauszniewski, McDonald et al., 2002). The DCS consists of eight items scored on a 6point Likert Scale from strongly agree (5) to strongly disagree (0) to indicate the degree to which a particular statement describes the respondent's current thoughts (Zauszniewski, 1995). Scores may range from 0 to 40, with higher scores indicating a greater number of positive cognitions (Zauszniewski, 1997). Acceptable internal consistency has been reported (alpha = .78) (Zauszniewski, 1995). Construct validity for the DCS was demonstrated by significant correlations in the expected 
directions $(p<.001)$ with measures of depression, resourcefulness, adaptive functioning, and life satisfaction ( $r s=.54,-.37,-.60$, and -.57 , respectively) (Zauszniewski, 1997).

The DCS has been tested with the Egyptian population as a measure of positive cognitions. It has been tested with older adults who relocated to retirement communities and has proven to be reliable and valid (Bekhet, Fouad, \& Zauszniewski, 2010). The reliability reported in Bekhet et al. was .89. Validity was demonstrated by significant correlations of the positive cognitions scores with measures of relocation controllability (Pressure to Move scale scores) and relocation adjustment in the expected direction (-.41 and .49 , respectively, $p<.001)$.

The psychometric properties of the Arabic version of the Depressive Cognition Scale (A-DCS) also has been tested and reported among those 170 first-year adolescents Egyptian nursing students (Bekhet \& Zauszniewski, in press). The questionnaire was assessed for internal consistency, homogeneity, and construct validity using factor analysis and convergent validity. Results indicated that Cronbach's alpha for A-DCS was .86. The homogeneity of the instrument was supported by item-to-total correlations between .30 and .70. Factor extraction generated only one factor with eigenvalues greater than 1, which is consistent with the English version. The A-DCS total score had a strong significant correlation with the Alienation Scale scores $(r=-.51, p<.01)$, indicating convergent validity. Detailed description of the Arabic version of the DCS has been reported elsewhere (Bekhet \& Zauszniewski, in press).

\section{Content and Face Validity of the Measures}

Following the translation of the measure, a blind back-translation was completed, during which two other bilingual experts converted the translated instrument into the original English, without having seen the original instrument (Brislin, 1986; Yu, Lee, \& Woo, 2004). Discrepancies between the original and translated instruments were then examined and decisions made about the equivalence of the two forms. Revisions were made in the translated Arabic measure until the two forms appeared to be equivalent.

A panel of three persons (two nursing faculty members and one medical doctor) who were bilingual (Arabic and English) reviewed the consistency of the translations and the grammar and structure of the Arabic language. This panel compared the English and the Arabic versions, item by item. After reaching a consensus on the consistency of the translations and back-translations of the scale as well as corrections of the Arabic language grammar and structure, an Arabic version of the DCS was produced. Detailed information about the content and face validity of the DCS has been reported elsewhere (Bekhet \& Zauszniewski, in press).

Resourcefulness was measured by the 28-item Resourcefulness Scale (Zauszniewski, Lai, \& Tithiphontumrong, 2006), a self-report scale that assesses an individual's tendencies to use self-help and help-seeking behaviors when faced with adverse situations (Zauszniewski et al., 2006). The Resourcefulness Scale consists of 28 items; 16 measure personal resourcefulness and 12 measure social resourcefulness (Zauszniewski et al., 2006). The 6-point scoring system has response alternatives ranging from 0 (not at all like me) to 5 (very much like me) (Zauszniewski, et al., 2006). Thus, scores may range from 0 to 140, with higher scores indicating greater personal and social resourcefulness (Zauszniewski et al., 2006). Internal consistency of the Resourcefulness Scale has been shown by Cronbach's alphas of $.83, .79$, and .85 for the total scale, and personal and social resourcefulness 
subscales, respectively (Zauszniewski et al., 2006). Construct validity was indicated by the presence of the two dimensions of resourcefulness (personal and social) in confirmatory factor analysis and demonstrated by substantial intercorrelation between the two subscales $(r=.41, p<.001)$

(Zauszniewski et al., 2006). The resourcefulness scale has been translated and tested with the older Egyptian adults who had been relocated, and the reliability found to be .78 (Bekhet et al., 2010). The Resourcefulness Scale has not been tested with the Egyptian nursing students before. However, the reliability of the Resourcefulness Scale in this study was .81 and the construct validity was demonstrated by correlation in the expected direction with measures of alienation and positive cognitions ( $r=-.27, p<.01 ; r=.24, p<.01$, respectively).

A self-report questionnaire was developed to measure individual characteristics, including age, gender, parents' education, number of siblings, number of family members, student's birth order, parents' presence in the family, student's relation with parents, family problems, student's privacy, and religious status.

\section{RESULTS}

The age range of the sample was 17 to 20 years, and $95.3 \%$ of the students' ages ranged between 1719 years (mean $=18$ years). There were 121 females $(71 \%)$ and 49 males (29\%). Approximately 37.6\% of the students' fathers had a college education, $34.7 \%$ had a high school or technical education (two years after high school), $24 \%$ had less than a high school education, and $3.5 \%$ had graduate/professional education. Among the student' mothers, $36.5 \%$ had less than a high school education, 35.9\% had a high school or technical education (two years after high school), $25.3 \%$ had a college education, and $2.4 \%$ had post graduate education. The number of siblings ranged from 0 to 8 , with a mean of $3 ; 51 \%$ of the sample reported 6 or more family members. In relation to birth order, $30 \%$ of the students were the second child, $28 \%$ were the first child, and $18 \%$ were the last child; $34.7 \%$ reported their birth order as the first child of their gender and $31 \%$ reported their birth order as the second child of their gender born in the family.

\section{Process Regulators: Positive Cognitions}

\section{Mediation}

Two steps of hierarchical regression were used to determine whether positive cognitions mediated the relationship between alienation and resourcefulness (Figure 1; steps 1 and 2). The mediating role of positive cognition would be supported if: (a) Variation in independent variable (alienation) predicts variation in the outcome variable (resourcefulness), (b) Variation in the independent variable (alienation) predicts variation in the mediator variable (positive cognitions) (Figure 1; step 2), and (c) prediction of resourcefulness by alienation would be altered when positive cognition was entered (Figure 1; step 2).

FIGURE 1 Mediating Effects of Positive Cognitions on the Relationship between Alienation and Resourcefulness. 
Step 1: Alienation $\stackrel{B=-.27(P=.001)}{\longrightarrow}$ Resourcefulness

Step 2: $\quad$ Positive Cognitions

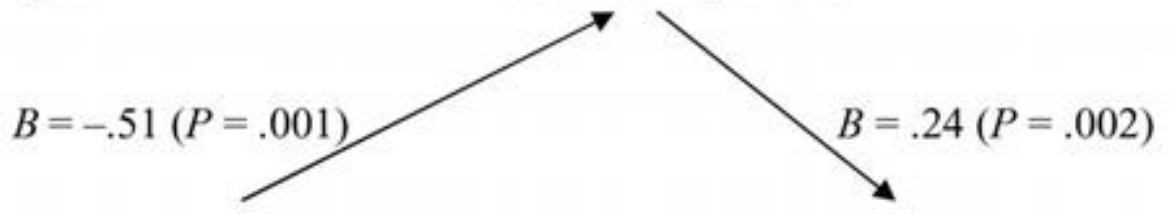

Alienation

$$
B=-.20(P=.05)
$$

Resourcefulness

The first condition was supported; when resourcefulness was regressed on alienation, the overall regression equation was also significant $(F(1,168)=13.37, p<.001)$ with $7 \%$ of the variance in resourcefulness explained by alienation. This analysis showed that alienation had a direct negative effect on resourcefulness $(B=-.27, p<.001)$, that is, as the level of alienation increased, the nursing student's resourcefulness decreased (Figure 1; step 1).

When positive cognitions were regressed on alienation, alienation had a direct negative effect on positive cognitions ( $B=-.51, p<.001)$. That is, as the level of alienation increased, adolescents' positive cognitions decreased (Figure 1 ; step 2 ). The overall regression model was statistically significant with $25 \%$ of the variance in positive cognitions being explained $(F(1,168)=58.47, p<.001)$.

Alienation was then entered in the first step of the regression model and positive cognitions were entered in the second step. Following step 1 , the model was significant $(F(1,168)=13.37, p<.001)$ and alienation accounted for $7 \%$ of the variance of resourcefulness. When positive cognitions were added to step 2 , the model remained significant $(F(2,167)=8.01 ., p<.001)$. When positive cognitions entered the equation (Figure1; step 2), there was a substantial drop in the beta weight of alienation, from $B=-.27$ to -.20 . The effect of alienation on resourcefulness continued to be significant; however, the level of significance dropped from $p<.001$ to $p<.05$, suggesting that the effects of alienation on resourcefulness may have been partially mediated by positive cognitions.

\section{Moderation}

To test for moderating effects, an interaction term was created by "centering" the scores on measures of alienation and positive cognitions, then multiplying the two. Baron and Kenny (1986) suggested that variables need to be centered in order to reduce the correlation of the interaction term with its component. Centering was achieved by subtracting the mean of each variable from each individual datum. To examine the moderating effect of positive cognitions on the relationship between alienation and resourcefulness (Figure 2), alienation and positive cognitions were entered together in the first step, followed by entry of the interaction terms in the second step. The regression model for both steps was significant $(F(2,167)=8.08, p<.001$, and $F(3,166)=7.67, p<.001$, respectively). In the first step, alienation and positive cognitions together accounted for nearly $8 \%$ of the variance in resourcefulness. The addition of the interaction term in step 2 contributed to the variance, which rose to $11 \%$; the interaction term was significant $(B=-.21, t=-2.54, p<.05)$. Thus, positive cognitions were 
found to moderate the effects of alienation on resourcefulness in the first year nursing students who participated in the study (Figure 2).

FIGURE 2 Moderating Effects of Positive Cognitions on Resourcefulness.

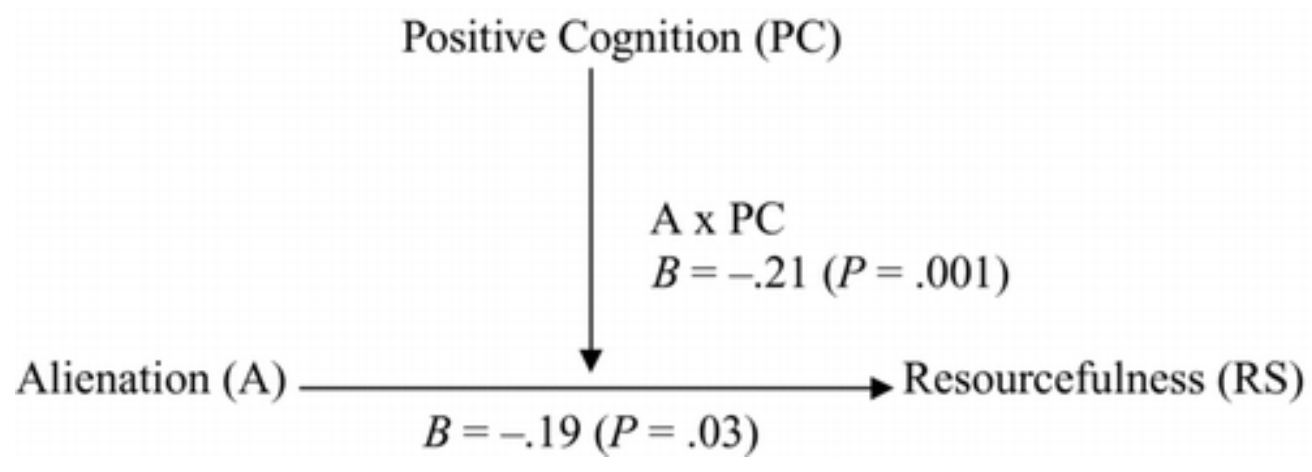

\section{Discussion}

This study examined the mediating and moderating effects of positive cognitions on the relationship between alienation and resourcefulness in first year nursing students in Egypt. Negative effects of alienation on positive cognitions may be related to the fact that when adolescents do not have a sense of belonging to family, school, and society, this might contribute to more negative thinking and vice versa. That is consistent with Zauszniewski's (2006) theory of resourcefulness, which suggests that antecedent factors (in this case, alienation) may influence intervening factors (in this case, positive cognitions) of adolescent nursing students.

In this study, positive cognitions had a direct positive effect on resourcefulness. In other words, as students' positive thinking increased, their individual resources for coping also increased. This is consistent with previous studies that found that fewer irrational beliefs in undergraduate students (Rosenbaum, 1980) and less negative cognition in African-American women (Zauszniewski, Picot, Debanne, Roberts, \& Wykle, 2002) were significantly related to higher levels of resourcefulness. In addition, studies have shown that more positive personal beliefs (Lai, 2005), more positive cognitions in relocated older adults (Bekhet et al., 2008), and more positive self-evaluation in family caregivers (Rosswurm, Larrabee, \& Zhang, 2002) were significantly related to greater resourcefulness. The findings supported Zauszniewski's (2006) theory of resourcefulness, which postulates that process regulators, including positive cognitions, can help one to overcome adverse situations by using the selfhelp and help-seeking behaviors constituting resourcefulness to achieve optimal functioning in daily activities.

The results of this study indicate that positive cognitions act as a moderator and partial mediator on the relationship between alienation and resourcefulness in this sample of nursing students. In fact, previous research suggested that positive cognitions has been found to function in both mediator and moderator roles (Bekhet, Fouad, \& Zauszniewski, 2010; Zauszniewski, Bekhet, \& Suresky, 2009).

Moderation and mediation are often examined in basic and applied research (Baron \& Kenny, 1986; Edwards \& Lambert, 2007). Moderation occurs when the effect of an independent variable (alienation) on a dependent variable (resourcefulness) varies according to the level of a third variable (the 
moderator, positive cognitions [PC]). Therefore, in the case of the moderator, the independent variable (alienation) interacts with the moderator variable (PC) to produce an effect on the outcome variable (resourcefulness). The results from prior research have indicated that psychological resources, including sense of coherence, hardiness, and self-efficacy, act as moderators that interact with other conditions to produce stress-buffering effects on health outcomes (Taylor\& Aspinwall, 1996). Similarly, positive cognitions interact with alienation to produce stress-buffering effects on resourcefulness. Since alienation interacts with positive cognitions to produce the effects on resourcefulness, intervention should be directed to decrease levels of alienation and increase levels of positive cognitions among nursing students.

The results from this study draw attention to the importance of identifying and reducing alienation encountered by adolescents nursing students as well as the need to focus on developing and testing interventions to strengthen one's positive cognitions in order to promote optimal resourcefulness in nursing students who might experience alienation. As first year nursing students, their sense of belonging can be enhanced by receiving the help and guidance needed to find their way in the new clinical environment. The new environment might be perceived by students as unreceptive and unwelcoming (Levett-Jones, Lathean, McMillan, \& Higgins, 2007); mentors should play a major role in supporting students and acting as champions or sponsors (Levett-Jones, Lathean, McMillan, \& Higgins, 2007). Individual counseling or group discussions can identify and reduce potential worries and stressors that the adolescents may have. Assessing students' attitudes toward the clinical environment, their strengths, and concerns is vital to facilitate adjustment to the new environment. In fact, promoting a sense of belonging in the clinical area could be the first step to promote sense of belonging to the society. Screening for alienation could be performed on first year nursing students for early detection and intervention.

The study points to a clear need to focus on organized groups that provide social support, and a sense of belonging to strengthen the adolescents' positive cognitions. Short-term cognitive therapy may be helpful for adolescents nursing students. Intervention programs should include helping students to use positive self-talk, reframe situations positively, change from their usual reactions, and explore new ideas. Intervention programs should help the students to practice using the positive cognitions strategies rather than just knowing them.

The theory of resourcefulness implies that alienation, an intrinsic factor, influences resourcefulness, and this relationship may be mediated or moderated by positive cognitions. However, it also is possible that students with limited resourcefulness may feel more alienated, as they have fewer learned coping mechanisms. Future research should look at the bidirectional relationship between these two concepts-resourcefulness and alienation-which would potentially change the model, its testing, and the implications of the findings.

Therefore, interventions also should be directed to increase students' personal and social resourcefulness. Social resourcefulness strategies include seeking professional help when needed, asking family and friends for support, and exchanging ideas with others. Personal resourcefulness strategies include learning how to organize daily activities, deal with life stressors by using positive selftalk, reframe situations positively, explore new ideas, and change one's usual reactions. Both personal and social resourcefulness are vital in predicting health outcomes (Zauszniewski, 2006). Furthermore, it 
has been found that those who are high in both personal and social resourcefulness had less anxiety, depression and better adaptive functioning as compared to those who were had high levels of social or personal resourcefulness (Zauszniewski, 2006). Future studies may consider testing the reliability and the validity of the Resourcefulness Scale with the Egyptian populations.

The results of this study indicated that positive cognitions (PC) had a partial mediating effect on the relationship between alienation and resourcefulness. In fact, the mediation occurs when the indirect effect of an independent variable (alienation) on a dependent variable (resourcefulness) passes through a mediator variable (PC). So, in this case, the effect of alienation on resourcefulness passed through PC (Baron \& Kenny, 1986; Edwards \& Lambert, 2007). In other words, alienation, as an intrinsic factor, affects resourcefulness and this relationship may be mediated by PC. Given the fact that PC acted as a partial mediator on the relationship between alienation and resourcefulness in this study, this raises the question as to whether PC is a stable or unstable construct (Hogh \& Mikkelsen, 2005). Given the cross-sectional design of the study reported here, is difficult to infer whether PC is open to change even after exposure to stressful or pleasant experience or cognitive therapy. However, research has indicated that cognitive therapy has been successful in improving problems with selfesteem, depression, and anxiety in adolescents (Rush \& Beck, 2000). Students' irrational beliefs can be challenged and the way they feel and behave can be changed by cognitive therapy (Rush \& Beck, 2000). This, in turn, can help decrease alienation and improve their sense of belonging. Students can be taught that the way they think influences their feelings and behaviors. Therefore, their irrational beliefs can be challenged and changed.

Helping students to identify the inaccurate beliefs that they might have about themselves along with any unrealistic aspirations would be the first step in changing their thinking and, consequently, their feelings and behaviors. It has been documented that the cognitive approach is very useful in changing self-image and enhancing self-efficacy beliefs, as well as modifying perceptions (Rush \& Beck, 2000). The use of video feedback can be very beneficial in helping students to change the way they approach a situation and thus their behaviors.

Additional longitudinal studies would be useful in determining the effects of positive cognitions interventions on levels of alienation among nursing students.

There were a number of limitations to this study related to methodological and sampling issues. Since the study was cross sectional, it assessed variables only at one point in time. Rosenbaum postulated that resourcefulness is learned throughout life (Rosenbaum, 1990); thus, measuring resourcefulness at a single point in time may not take into account previous resourcefulness. Further, knowing resourcefulness skills does not necessarily mean that nursing students will apply them. A longitudinal study would be useful in examining the causal effects of positive cognitions and resourcefulness among adolescent nursing students over time. An experimental study could examine the causal effects of training programs that strengthen positive cognitions and teach resourcefulness skills to adolescent nursing students. Future studies should also consider comparing degrees of positive cognition and alienation across the four years of nursing school, as the basis for planning tailored interventions. A post-intervention longitudinal study could test both the effectiveness and the persistence of the intervention and provide a clear picture of its long-term effects and the implications for proper management and prevention of further adolescent problems. 
Declaration of interest: The authors report no conflict of interest. The authors alone are responsible for the content and writing of this paper.

\section{REFERENCES}

Abd El Monem, A. M. (1988). Alienation and psychological changes among normal and blind university students. Unpublished doctoral dissertation. Alexandria University, Egypt.

Ahmadi, J., Toobaee, S., \& Alishahi, M. (2004). Depression in nursing students. Journal of Clinical Nursing, 13(1), 124.

Baron, R. M., \& Kenny, D. A. (1986). The moderator-mediator variable distinction in social psychological research: Conceptual, strategic, and statistical considerations. Journal of Personality and Social Psychology, 51(6), 1173-1182.

Bekhet, A., Abd El-Dayem, S., Naguib, M., \& ElGuinidy, M. (April, 2005). Alienation among diploma nursing school students in Alexandria (abstract). Proceedings from the 7th Annual Conference of the International Society for Psychiatric-Mental Health Nurses (ISPN). Pittsburgh, Pennsylvania.

Bekhet, A., Fouad, R., \& Zauszniewski, J. A. (2010, October). The role of positive cognitions in Egyptian elders relocation adjustment. Western Journal of Nursing Research. [Epub ahead of print] PMID: 20935215.

Bekhet, A., \& Zauszniewski, J. A. (in press). Psychometric properties of the Arabic version of the depressive cognition scale in first year adolescents Egyptian nursing students. Journal of Nursing Measurement.

Bekhet, A., Zauszniewski, J. A., \& Wykle, M. (2008, February). Midwest Nursing Research Society Sage Best Paper Award: Milieu change and relocation adjustment in elders. Western Journal of Nursing Research, 30(1), 113-129

Brislin, R. W. (1986). The wording and translation of research instruments. In W. J. Lonner \& J. Berry (Eds.), Field methods in cross-cultural research (pp. 137-164). Beverly Hills, CA: Sage.

Dean, D. G. (1961). Alienation: Its meaning and measurement. American Sociological Review, 26(5), 753-758.

Edwards, J. R., \& Lambert, L. S. (2007). Methods of integrating moderation and mediation: A general analytical framework using moderated path analysis. Psychological Methods, 12(1), 1-22.

Fortinash, K. M., \& Worret, P. H. (2007). Psychiatric nursing care plans (5th ed.) St. Louis, MO: Mosby.

Gulliver, P., \& Begg, D. (2007). Personality factors as predictors of persistent risky driving behavior and crash involvement among young adults. Journal of the International Society for Child and Adolescent Injury Prevention, 13(6), 376-381.

Hogh, A., \& Mikkelsen, E. G. (2005). Is sense of coherence a mediator or moderator of relationships between violence at work and stress reactions? Scandinavian Journal of Psychology, 46, 429437.

Lefton, L. A., \& Brannon, L. (2003). Psychology (8th ed.). Boston, MA: Allyn and Bacon.

Levett-Jones, T., \& Lathlean, J. (2008). Belongingness: A prerequisite for nursing students' clinical learning. Nurse Education in Practice, 8(2), 103-111.

Levett-Jones, T., Lathlean, J., McMillan, M., \& Higgins, I. (2007a). Belongingness: A montage of nursing students' stories of their clinical placement experiences. Contemporary Nurse, 24(2), 162-174

Link, L. B. Robbins, L., Mancuso, C. A., \& Charlson, M. E. (2004). How do cancer patients who try to take control of their disease differ from those who do not? European Journal of Cancer Care, 13, 219-226

McGrath, C., Jordens, C. F., Montgomery, K., \& Kerridge, I. H. (2006). "Right" way to "do" illness? Thinking critically about positive thinking. Internal Medicine Journal, 36, 665-668. 
POLICY Project. (2003). Adolescents and reproductive health in Egypt: Status, policies, programs, and issues. Retrieved from

\section{http://www.policyproject.com/pubs/countryreports/ARH Egypt.pdf}

Rayce, S. L., Holstein, B. E., \& Kreiner, S. (2009). Aspects of alienation and symptom load among adolescents. European Journal of Public Health, 19(1), 79-84.

Rice, F. P., \& Dolgin, K. G. (2008). The adolescent development, relationship, and culture (12th ed.). London, England: Pearson.

Rosenbaum, M. (1980). A schedule for assessing self-control behaviors: Preliminary findings. Behavior Therapy, 11, 109-121.

Rosenbaum, M. (1990). Learned resourcefulness on coping skills, self-control, and adaptive behavior. New York, NY: Springer.

Rosswurm, M. A., Larrabee, J. H., \& Zhang, J. (2002). Training family caregivers of dependent elderly adults through on-site and telecommunications programs. Journal of Gerontological Nursing, 28(7), 27-38.

Rush, A. J., \& Beck, A. T. (2000). Cognitive therapy. In H. I. Kaplan \& B. J. Sadock (Eds.), Comprehensive textbook of psychiatry (7th ed.; pp. 2167-2178). Baltimore, MD: Williams \& Wilkins

Schabracq, M., \& Cooper, C. (2003). To be me or not to be me: About alienation. Counseling Psychology Quarterly, 16(2), 53-79.

Steinberg, L. (2010). Adolescence (9th ed.). New York, NY: McGraw-Hill.

Taleghani, F., Parsa Yekta, Z., \& Nasrabadi, A. N. (2006). Coping with breast cancer in newly diagnosed Iranian women. Issues and Innovations in Nursing Practice, 54(3), 265-273.

Taylor, S. E., \& Aspinwall, L. G. (1996). Mediating and moderating stressors in psychosocial stress. In H. B. Kaplen (Ed.), Psychosocial stress: Perspectives on structure theory, life course and methods (pp. 71-110). San Diego, CA: Academic.

Younger, J. (1995). The alienation of the sufferer. Advances in Nursing Science, 17(4), 57-59.

Yu, D. S. F., Lee, D. T. E, \& Woo, J. (2004). Issues and challenges of instrument translation. Western Journal of Nursing Research, 26(3), 307-320.

Zauszniewski, J. A. (1994). Health seeking resources and adaptive functioning in depressed and nondepressed adults. Archives of Psychiatric Nursing, 8(3), 159-168.

Zauszniewski, J. A. (1995). Development and testing of a measure of depressive cognition in older adults. Journal of Nursing Measurement, 3(1), 31-41.

Zauszniewski, J. A. (1997). The Depressive Cognition Scale: Further psychometric evaluation. Journal of Nursing Measurement, 5(2), 191-200.

Zauszniewski, J. A. (2006). Resourcefulness: A new mid-range theory. In J. J. Fitzpatrick \& M. Wallace (Eds.), Encyclopedia of nursing research (pp. 256-258). New York, NY: Springer.

Zauszniewski, J. A., Bekhet, A., \& Suresky, M. J. (2009, December). Effects on resilience of women family caregivers of seriously mentally ill adults: The role of positive cognitions. Archives of Psychiatric Nursing, 23(6), 412-422.

Zauszniewski, J. A., Lai, C. Y., \& Tithiphontumrong, S. (2006). Development and testing of the Resourcefulness Scale for Older Adults. Journal of Nursing Measurement, 14 (1), 57-68.

Zauszniewski, J. A., \& Martin, M. H. (1999). Developmental task achievement and learned resourcefulness in healthy older adults. Archives of Psychiatric Nursing, 1, 41-47.

Zauszniewski, J. A., McDonald, P. E., Krafcik, K., \& Chung, C. W. (2002a). Acceptance, cognitions, and resourcefulness in women with diabetes. Western Journal of Nursing Research, 24(7), 728741. 
Zauszniewski, J. A., Picot, S. J., Debanne, S. M., Roberts, B. L., \& Wykle, M. L. (2002b). Psychometric characteristics of the Depressive Cognition Scale in African American women. Journal of Nursing Measurement, 10(2), 83-95. 